\title{
The Impact of Creditworthiness on Financial Well-Being, Anxiety, Depression, Hopelessness, and Suicide
}

\author{
Cathie Hughes \\ Omega Graduate School
}

Creditworthiness, defined by financial institutions' credit scoring systems, classify people according to categories of risk. Decision metrics and scorecard implementations are determinants that serve as a financial gateway to access the most basic human needs for safety and wellbeing. For those with no credit or credit scores less than excellent, escalating negative circumstances lead to adverse life events associated with financial stress, widening socioeconomic disparities, and worsening biopsychosocial conditions. The impact of creditworthiness on financial wellbeing and negative psychological constructs were explored through quantitative research with a focus on improving these factors through a credit restoration intervention.

Keywords: creditworthiness, financial wellbeing, credit scores, debt, depression, hopelessness, suicide, COVID, socioeconomic determinants of health

\section{INTRODUCTION}

This research focused on adults who were seeking professional help due to over-indebtedness, harassing calls from creditors, inability to obtain affordable loans, and other negative credit-related difficulties who could benefit through receiving credit restoration services. The purpose of the research was to evaluate whether improving creditworthiness improved financial wellbeing indicators and decreased indicators of anxiety, depression, and hopelessness. The assumption was poor creditworthiness created financial stress, which contributed to debilitating psychological conditions. A problem with unfavorable creditworthiness, as defined by negative credit reports and less than excellent credit scores, is that poor credit contributes to high interest rates that induce a downward cycle of financial stressors. The application of negative reporting and high interest rates prompt psychosocial stressors that are key risk factors that lend to depression, hopelessness, anxiety, social isolation, legal issues, debilitating debt, destruction of family relationships, poverty, and suicidal behaviors.

\section{LITERATURE REVIEW}

A review of the current literature examined measurable constructs related to the thesis. These constructs include financial well-being and well-being, subjective and objective well-being, financial stress, hopelessness, depression, anxiety, suicide, and creditworthiness. Research related to the positive construct of hope was reviewed. The science of hope was identified as a field that informs research on the impact of 
creditworthiness on negative psychological attitudes and behaviors. The relationship between well-being, demographics, and population groups was reviewed.

\section{Financial Well-Being}

Financial Well-Being (FWB) is a measurable construct consisting of both objective and subjective factors that reference adequacy of financial resources to live comfortably and satisfaction with "categories of financial resources" (Xiao, 2016, p.15). FWB frames modifiable and non-modifiable factors and behaviors associated with the broader and overarching construct of well-being. According to The Assessment and Management of Risk for Suicide Working Group (2013), modifiable factors include psychosocial and socioeconomic conditions that can be subject to an intervention. Non-modifiable and preexisting factors include gender, age, race, sexual orientation, family history of trauma and mental illness, education level, and religious or cultural beliefs (pp. 25-27). Sorgente, Totenhagen, and Lanz (2021) noted the complexities of FWB conceptualizations but offered a definition adopted from different studies. These authors "(e.g., Cherney et al., 2020; Iannello et al., 2022; Sogente and Lanz, 2019) ... define financial wellbeing as a positive financial condition that has an objective and a subjective side" (p. 3). Joo (2003) defined financial wellness as a "comprehensive, multidimensional concept incorporating financial satisfaction, and (sic) objective status of a financial situation, financial attitudes, and behavior that cannot be assessed through just one measure" (p.1). Joo (2008) later defined FWB as feeling financially free from anxiety, being healthy, and feeling happy based on one's financial circumstances (pp. 21-31). Sorgente, Totenhagen, and Lanz (2021) elaborated, "subjective financial well-being consists of an individuals' subjective evaluation with respect to his or her financial condition. This evaluation may include emotional...and cognitive... evaluation" (p.3).

Brüggen, Hogreve, Holmlund, Kabadayi, and Löfgren (2017) noted the importance of financial wellbeing research for individuals, households, and societies. Comerton-Forde et al. (2020) noted while lacking rigorous measurements, the complexity and importance of FWB are of considerable concern for societal issues and researchers. Salignac, Hamilton, Noone, Marjolin, and Muir (2019) recognized the need for programs to educate populations to improve households' FWB; however, asserting FWB remains "inadequately conceptualized and inconsistently defined" (p. 1581). A financial well-being scale measuring five aspects of subjective FWB (Sorgente and Lanz, 2019) was developed and tested specifically for emerging adults. These researchers stressed that with scant research distributed across several disciplines, it is essential to examine FWB behaviors and indicators, constructs, and interventions, which can help inform financial institutions of opportunities to improve financial well-being. According to bin Hassan, Hassan, Kassim, and Said (2021), a systematic literature review was lacking for assessing the relationship between FWB and psychological influences, although many studies were conducted on the relationship between mental health and financial well-being (p.93).

Subjective and objective indicators of FWB are measurable. According to Xiao (2016), financial satisfaction is the most common measurement of subjective well-being (p.15), while satisfaction with income, savings, and adequate financial resources are other measurable FWB indicators (pp. 15-17). Xiao (2016) reported that "income is identified as an important determinant of financial satisfaction" (p.17). Financial position is a subjective indicator of FWB and "an important determinant of psychological wellbeing and overall life satisfaction (Gray, 2013, p. 159). Barnard (2016) stated, "Without exception, research exploring income and financial and psychological well-being dynamics apply subjective well-being (SWB) measures as the primary indicator of psychological well-being (p. 648). Marum et al. added that low income was less likely to be associated with psychological stress than the objective well-being indicator of an inability to meet expenses (2014). Economic hardship was identified as having a major psychological impact on SWB (Son \& Wilson, 2017; Starkey et al., 2012). Investigating the emerging adults' population, Iannello, Sorgente, Lanz \& Antonietti (2021), moderating for uncertainty and ambiguity tolerance patterns, tested the relationship of subjective FWB on this group's subjective and psychological well-being.

Lanz, Sorgente, and Danes (2020) examined to what degree a families' "economic enmeshment" influenced the SWB and OWB of emerging adults. Objective FWB indicators denote unbiased and quantifiable aspects of a person's economic condition (Gerrans, Speelman, \& Campitelli, 2014). Objective 
indicators of financial well-being include one's financial standing or household income, debt-to-income ratio, expenditures, asset, and net worth (Starkey et al., 2012, p. 84; Xiao, 2016, p. 15), "socioeconomic characteristics such as low income, low education level, debt and unemployment" (Dijkstra-Kersten et al., 2015 , p. 660) and considered as most significant, "real gross disposable income per capita" (RăileanuSzeles, 2015, p. 703). Several assessments were found in examining the relationship between mental health and FWB. "A total of 6 instruments for financial wellbeing and 12 instruments for mental health were found..whereby (sic) most instruments assessed different dimensions of mental well-being with different subscales (bin Hassan, Hassan, Kassim, and Said, 2021, p. 93).

\section{Well-Being}

Well-Being (WB) is an interdisciplinary field of study that has important implications for several disciplines including psychology, health, economics, public policy, and society. Well-being measurements, definitions, and theories differ based on the lens through which research is purposed. The last decade produced literature that attempts to bridge disciplines and approaches within the broad framework of Wellbeing (Răileanu-Szeles, 2015; Linton, Dieppe, Medina-Lara, Watson, \& Crathorne, 2016). Linton et al. (2016) named six thematic well-being dimensions, including mental being, which was used interchangeably with psychological, physical, social, spiritual, and personal functioning, and one global or overall wellbeing construct (p. 11). Barrett, Hogreve, and Brüggen (2021) emphasize distinctive and measurable elements of wellbeing, namely "physical, mental, psychosocial, financial, and functional" (p.3).

Research for this study focused on the constructs of financial well-being (FWB) within the context of overall well-being and the two categorical indicators referred to as objective and subjective indicators of financial well-being. FWB is also an interdisciplinary field of study with varying definitions among scholars (Ghina and Sukarno, 2021). The Consumer Financial Protection Bureau (2015) stated "rigorously identified links" between "financial knowledge, understanding, and actions taken" and "financial outcomes have yet to be established (p. 5). FWB is defined in the detailed Consumer Financial Protection Bureau (CFPB) report, although research initiatives are ongoing. According to the CFPB research findings, FWB drivers "fall into three categories: financial behaviors, financial knowledge, and personal traits" (p. 5). Each of these categories supports several hypotheses, which together suggest "how particular behaviors, skills, and traits appear to support or predict financial well-being, given a certain level of opportunity" (p.7).

\section{Well-Being and Populations}

Culture, sociocultural context, and demographic characteristics may significantly impact attitudes and decisions about money and affect financial practices and behaviors. Danes, Garbow, and Jokela (2016) define culture as referring to the "ways people view the world and represent people's orientation to all living things and their reality" (p. 61). Sociocultural contextualization is essential for understanding populations because "subjective indicators such as values and beliefs are the best indicators of decision making" and are "critical in financial education and counseling efforts" (Danes, Garbow, \& Jokela, 2014, p. 61). The COVID-19 pandemic crisis exposed people to overindebtedness and highlights the need for financial literacy in addressing debt. Kurowski (2021) relates, "lower debt literacy causes individuals to finance themselves at a greater cost (p. 3), whereby "the lack of financial and debt literacy of borrowers may lead to loans being taken by people who are unable to repay them" (p. 1). There are significant relationships between these sociocultural factors and financial stress and financial well-being, and psychosocial symptoms. Financial stress can increase the risk of major depressive disorder (MDD) and impact financial well-being (Sabri and Zakaria, 2015, pp. 827-828), which is exacerbated by biopsychosocial, socioeconomic, sociocultural, and demographic factors.

Environmental and social conditions can affect population groups' capacity to self-manage healthy behaviors, and economic strains are attributed to lower health self-efficacy behaviors (Tucker-Seeley, Mitchell, Shires, and Modlin, 2015, pp. 22-23). Tucker-Seeley et al. found that "Across a range of health outcomes, African American men fare poorly compared to other populations" (p. 2), and this population is "exposed to many social and environmental conditions and stressors that have a negative impact on their health and health behavior" (p. 2). Tucker-Seeley et al. reported that this population has lower wages, the 
highest unemployment rates, and "are more likely to report hardships than whites, even after controlling for demographic and other socioeconomic indicators" (p. 3). Barr (2019) developed a model depicting "ways in which social inequality affects health status" (p. 95). This model illustrates "the probable causal pathways through which low social status results over time in poor health or premature death" (p. 95).

Additional environmental and social conditions, such as the outbreak of the COVID-19 pandemic coupled with stay-at-home restrictions, negatively affect wellbeing across several domains, including mental, physical, social, functional, and financial wellbeing (Barrett, Hogreve, and Brüggen, 2021). Additional concerns related to the pandemic contributed to compromised parenting and an increase in individual and family stressors, and families around the globe have "a new range of stressors that threaten their health, safety, and economic well-being" (Brown, Doom, Lechuga-Peña, Watamura, and Koppels, 2020, p. 2). Friedline, Chen, and Morrow (2020) cited the Great Recession of 2007 and the COVID-19 pandemic as drivers negatively impacting families' financial well-being and ability to fully meet reoccurring financial obligations. The authors' literature review on financial stress and well-being confirmed the need to emphasize the relationship to the economy and economic environments.

American Indian tribes share core values that are "grounded in the family context and impact financial decision making and financial behaviors" (Danes, Garbow, and Jokela, 2016, p. 61). Often, entire tribes consider members to be from one extended family. Demands are placed on financial resources because of culturally-based expectations (p. 69), reflective of a collectivist culture in which "only one resource is (sic) used to achieve well-being. "Financial planning reflects the challenges of resource management for this population's "present-time orientation grounded by their spiritual beliefs" (p. 69).

College students with student loan debt and low net worth experienced financial stress, which has led to a greater number of students dropping out of college "due to financial stress rather than from academic failure" (Britt, Canale, Fernatt, Stutz, \& Tibbetts, 2015, p. 172). Financial stress was attributed to "college student attrition, academic performance, student retention, and general health and well-being of college students" (p. 173). Cherney, Rothwell, Serido, and Shim (2020) examined the role of family socioeconomic factors, student debt, and SFWB during emerging adulthood, reporting a substantial and negative association with student debt. Bousfield, Phillips, D'Angelo, and van Stolk (2021) found a close tie between mental health, economic difficulties, and FWB. Compared with older age groups, financial concerns for younger people lead this population to be "approximately twice as likely as their older counterparts to have poorer mental health (p. 1).

Adjustment challenges among returning Iraq and Afghanistan war veterans were found to have a "strong association between post-deployment adjustment and financial well-being" (Elbogen, Johnson, Wagner, Newton, \& Beckham, 2012, p. 673). Psychosocial factors, including. Post-Traumatic Stress Disorder (PTSD), Major Depressive Disorder (MDD), and Traumatic Brain Injury (TBI) negatively impacted employment and income. According to Elbogen et al., while data demonstrated a "causal link between financial problems and post-deployment adjustment" (p. 674), researchers could not conclude "whether financial problems cause post-deployment adjustment or vice versa" (p. 674). It was determined to be possible that "financial strain and post-deployment are mutually reinforcing and can create a downward spiral for veterans' readjustment" (p. 674). Objective factors associated with soldier transitions may negatively impact family income. Bell, Nelson, Spann, Molloy, Britt, and Goff (2014) report working military spouses are frequently forced to leave their jobs with each transition. While they are more likely to seek employment than civilians, they are "less likely to be employed.... have a $26 \%$ unemployment rate and earn $25 \%$ less than their civilian counterparts" (p. 41). Soldiers' "carry a heavier debt load and pay more penalties than their civilian counterparts" (p. 41) and use predatory payday loans and "high-cost nonbank lending sources" (p. 41). Other factors lead to personal financial difficulties among military families, including the inability to rent or sell their homes at a price that covers the outstanding mortgages.

\section{Financial Stress, Debt, Social and Socioeconomic Determinants of Health}

Stress is an emotional, physical, or mental response to pressure, strains, and other tensions resulting from demanding adverse or traumatic events. Financial stress is a subjective reaction to economic hardship. Among the alarming levels of stress experienced by Americans, "financial stressors are the most 
prominently cited and include concerns about having enough money, housing costs, and job stability" (Bell et al., 2014, p. 41). Researchers cited a relationship between financial stress and psychosocial stressors, including depression, anxiety, suicidal behaviors, and social supports (Dijkstra-Kersten et al., 2015; Dow et al., 2020; Son \& Wilson, 2015; Starkey et al., 2013; Sweet et al., 2013; Thompson, 2015; Valentino et al., 2014). Valentino et al. (2014) associated parents' depression with marital conflict and adverse effects on child development (p.52). Other causal relationships related to financial stress included medical expenditures and risk of having medical expenditures (Barcellos and Jacobson, 2015; Osborn et al., 2017), intimate partner violence (IVP) (Bonomi, Trabert, Anderson, Kernic, \& Holt, 2014; Hoge, 2014; SchwabReese et al., 2016), and short-term debt, especially for populations nearing retirement and those who were less educated or unmarried (Berger, Collins, and Cuesta, 2016). Raab, Mackintosh, Gros, and Morland (2015) highlighted PTSD and depression as associated with decreased life satisfaction and financial problems.

Other researchers framed financial stress as a response to several factors (Starkey, 2013; Turunen \& Hiilamo, 2014; Valentino, 2014; Barcellos \& Johnson, 2015). Starkey et al. (2013) referred to the inability to meet financial responsibilities, a perceived or actual state of debt exceeding income, an inability to manage money, provide for needs, pay bills, and to repay debts (Starkey et al., 2013, p. 84). Turunen and Hiilamo (2014) identified factors such as having lower disposable incomes and housing values, being delinquent and defaulting on loans and having credit card or loan debts. Valentino et al. (2014) asserted the contribution of a lack of social support and depressive symptoms as contributors to financial stress. Barcellos and Jacobson (2015) stated medical-related bills and collections as contributory factors.

Debt is a construct also referred to as indebtedness (Bell, 2014; Ellis, 2014; Sweet,2013). The state of debt or indebtedness is a "resource constraint in that it limits the ability to use current income for current expenses" (Bell et al., 2014, p. 43). Debt is a financial stressor associated with a multitude of adverse psychological, physiological, and general health conditions (Frasquilho, 2016; Institute of Medicine, 2014; Sabri, 2015; Sweet, 2013; Pearlin, 2013). Psychological and mental health correlates include anxiety, depression, hopelessness, and suicidal behaviors (Dow, Godøy, Lowenstein, \& Reich, 2020; Frankham, Richardson, \& Maguire, 2020; Starkey, 2013; Marum, 2014). Physiological factors include metabolic and cardiovascular disease processes, such as autoimmune, diabetes, and heartdisease (Institute of Medicine, 2014; Sweet, 2013). General health conditions include health behaviors such as diet, physical activity, and substance use (Institute of Medicine, 2014).

\section{Socioeconomic Status and Determinants of Health}

Financial debt is a critical indicator of creditworthiness and credit-unworthiness that impacts individuals and families' psychological, social, socioeconomic, health, and general well-being. While debt is known to be a powerful indicator of negative socioeconomic status (SES), this relationship has been "largely neglected in research on social and economic determinants of health" (Sweet et al., 2013, p. 94). Barr (2019) uses income to measure SES, either income earned by the individual or "total income earned by all the people in the household of which the individual is a member" (p. 42). Health is a holistic construct that embodies multiple factors associated with community and personal well-being. In their literature review of 99 self-reported measures for assessing adult well-being, Linton et al. (2016) reported that authors often used the World Health Organization's (WHO) definition of health as "a state of complete physical, mental, and social well-being, not merely absence of a disease" (p.10). Linton et al. defined determinants of health as "those factors thought to influence how people think and feel" (p. 10). The Social Determinants of Health (SDoH) framework, "useful for analysis and policy recommendations," is an "approach to understand health inequalities" (Lundberg, 2020, p. 473). Lundberg differentiates SDoH from other types of poor health, for example, accidents, infectious diseases, and non-communicable diseases. Instead, "it is the population regularities of poor health, how these regularities are created and how they may be counteracted that is the issue" (p. 474). Artiga (2018) describes social determinants of health as "the conditions in which people are born, grow, live, work, and age. They include factors like socioeconomic status, education, neighborhood, and physical environment, employment, and social support networks, as well as access to care" (para. 3). Artiga highlights the role of financial well-being and social determinants 
of health. "There is a growing recognition that social and economic factors shape individuals' ability to engage in healthy behaviors... Further, evidence shows that stress negatively affects health across the lifespan and that environmental factors may have multi-generational impacts" (para. 4). As a holistic measure of an individual's entire living situation and life experience, "Addressing social determinants of health is not only important for improving overall health, but also for reducing health disparities that are often rooted in social and economic disadvantages" (para. 4). In the United States, the role of social and behavioral factors on health disparities and health policy has been largely ignored (Adler et al., 2016, p. 2). Health disparities stemming from socioeconomic factors, such as debt, credit unworthiness, and financial stress, are not inevitable but are modifiable. Investment in medical and clinical care does not equate to investment in health and "may yield smaller improvements in population health than equivalent investments that address social and behavioral determinants" (p. 2).

The Institute of Medicine (2014) produced a report addressing the determinants of health constructs. The report found "a concrete approach to including social and behavioral determinants of health in the clinical context to increase clinical awareness of the patient's state, broadly considered, and to connect clinical, public health, and community resources to work in concert" (np) and to address health disparities among United States population groups (p. 21). Consistent with Involution (2017) and Adler et al. (2016), the Institute of Medicine (IOM) reported on recent decades of research, which found that social, behavioral health, and psychological factors contributed to the onset and the progression of disease (p. 21). The IOM report contributes to theliterature on the determinants of health and the role of financial stress on psychological (e.g., depression) and behavioral (suicidal behaviors) on objective and subjective personal well-being. Economic pressures such as debt, unemployment, underemployment, workplace problems, and financial stress are socioeconomic Determinants of Health (DoH) that affect psychological and mental conditions and "health and health disparities" (IOM, 2014, p. 95).

\section{Depression, Debt, Financial Stress}

Berger et al. (2016) cited a relationship between debt and indicators of psychological issues. "There remains the potential that lenders offering high-cost short-term debt will target disadvantaged populations by offering 'easy' solutions to short-term cash flow problems, which serve to exacerbate both indebtedness and the client's mental health problems" (p. 55). Starkey et al. (2012) reported financial stress to be one of the most critical causal factors for depression and depressive symptoms. Depression results in a considerable "burden on the individual and society" (Löwe et al., 2010, p. 86) and is a concern for public health (Serafini et al., 2016, p. 122).

According to Serafini et al. (2016), major depressive disorder "is a common and disabling psychiatric condition affecting approximately $2.5 \%$ of the general population... and (sic) has been suggested to become the second-highest burden of disease by 2020" per the World Health Organization (p. 123). Starkey et al. (2012) cite several negative financial events that induce financial stressors. These include events such as "receiving overdue notices from creditors and collection agencies, issuing checks with funds insufficient to cover them, getting behind on bill payments, family money squabbles, and not being financially prepared for emergencies or major life events (p. 85). Financial stress levels increase according to the frequency of negative stressors, and cumulative instances of sporadic stressor events "may prove to be more detrimental over time" (p. 85). The effect of financial stress and economic hardship on children, families, and households intensifies the likelihood of depressive symptoms and the emotional health of all concerned. "It appears that as financial distress increases, individuals may experience a myriad of stress-related mental and physical symptoms and illnesses (p. 85). Berger et al. (2016) "There remains the potential that lenders offering high-cost short-term debt will target disadvantaged populations by offering 'easy' solutions to short-term cash flow problems, which serve to exacerbate both indebtedness and the client's mental health problems" (p. 55).

\section{Anxiety}

Anxiety has many aspects, is a widespread societal condition, and is associated with several types of anxiety disorders. The Diagnostic and Statistical Manual of Mental Disorders (DSM-5) lists 12 differential 
diagnoses (American Psychiatric Association, 2013, pp. 195-195). The "original" group of anxiety disorders are "Panic Disorder, Generalized Anxiety Disorder (GAD), Society Anxiety Disorder, [sic] Obsessive-Compulsive Disorder (OCD), and PTSD” (Roy-Byrne, 2015, p. 191). According to Roy-Bryne, "Anxiety may be one of the most prevalent psychiatric symptoms in the general population (p. 192) and is "one of the most vexing and difficult problems encountered by the practicing psychiatrist" (p. 193). Anxiety and depression are the most prevalent orders in the general population and outpatient treatment (Kroenke, Spitzer, Williams, \& Löwe, 2009, p. 613). These are often co-morbid conditions, and "when they co-occur, the disability is even greater" (p. 613). There are several types of anxiety disorders. They "share features of excessive fear and anxiety and related behavioral disturbances" (American Psychiatric Association, 2013 , p. 189). Anxiety is worry over a perceived future threat and is associated with "objects or situations that induce fear, anxiety, or avoidance behavior and the associated cognitive ideation" (p. 189), whereas stress can bring on brief instances of anxiety or fear, and persistent or excessive conditions last six or more months in adults (p. 191). Clinical diagnosis takes "cultural contextual factors into account" (p. 189).

\section{Hopelessness, Depression, Anxiety, Suicide Hopelessness}

According to Aish and Wasserman (2001), hopelessness is a crucial psychosocial construct that refers to three cognitive features (p. 367). Aaron Beck and his colleagues identified these features as "a negative view of the self, of the self in relation to the world and of the self in relation to the future" (p. 367). Fraser et al. (2014) defined hopelessness as the "subjective appraisal of negative expectations about the occurrence of highly valued outcomes coupled with the sense that one lacks control over desired events in the future" $(p, 1)$. Because of its relation to mental and physical health conditions, hopelessness is essential to psychosocial epidemiology (p. 1). Hopelessness is identified as a psychological indicator of suicidality, a shared affectation in suicidal individuals (Overholser \& Ridley, 2016, p. 378), and can be a predictor of future suicide risk (Hawton, Comabella, Haw, \& Saunders, 2013). Zhang and Li (2013) used hopelessness as a control variable in testing the association between depression and suicide (p. 790).

\section{Hopelessness and Depression, Anxiety, Suicide}

Hopelessness and depression are co-morbid conditions (Aish \& Wasserman, 2001; Huen, 2015; Kocalvent, 2016; Zhang, 2013). Beck et al. (1974) cite hopelessness "as one of the core characteristics of depression" (p. 861) and suicide and acknowledged that a strong relationship between hopelessness and depression has been widely implicated in other psychosocial and physical conditions. The Institute of Medicine (2014) identified depression, anxiety, and hopelessness as three of the four psychological negative moods and affected captured as social and behavioral indicators and measures for inclusion in Electronic Health Records (EHR). These interrelated constructs, in combination with anger/hostility, were found to occur throughout one's life, starting in childhood (p. 78). Furthermore, "Disorders of anxiety and depression are often co-morbid, and extreme feelings of hopelessness are signs of depression" (p 79).

\section{Hope}

Huen, Ip, Ho, and Yip (2015) found "hope can act as a resilience factor that buffers the impact of hopelessness on suicidal ideation... and (sic) may be a promising avenue for suicide prevention" (p.1). This view is based on empirical research found in the literature (p. 2). Huen et al. (2015) reported that "low-hope individuals fail to generate alternative pathways either to achieve a blocked goal or to formulate new attainable goals, and thus are prone to suicidal ideation in the face of stressors" (p. 3). These researchers investigated hope as "a resilience factor which buffers the strength of the association between hopelessness and suicidal ideation" (p. 3). The rationale used in the research was built upon other researchers' framework (Johnson et al., 2011) that wrote of factors that buffer individuals or create resilience to suicidality amid stressors. Huen et al. (2015) write that in the context of their research, "The resilience factor, i.e., hope...interacts with the risk factor.... hopelessness...to reduce the negative impact of the risk factor on an outcome of suicidality" (p. 3 ). 


\section{CREDIT-RESTORATION AND CREDITWORTHINESS}

Credit Restoration is an intervention that consists of services designed to improve an individual's creditworthiness, which can positively contribute to reducing debt and the financial stress and psychosocial indicators associated with indebtedness. Findings obtained in the pilot research study on the impact of creditworthiness on financial well-being, anxiety, depression, and hopelessness suggest the need to enhance or create services programs and interventions as collaborative interdisciplinary initiatives. Within the context of the research study, credit restoration is defined as services offered by legal, legitimate, accredited, licensed, and bonded credit servicesorganizations. The services address the three pillars of credit repair based on credit reporting compliance with the Fair Credit Act. These pillars require that the information maintained on credit reports is $100 \%$ accurate with no missing or additional information, that the information is $100 \%$ verifiable from the reporting source, and information is $100 \%$ in compliance with the correct statutes of limitations of aging data. The restoration process involves ensuring that the credit bureaus comply with the credit repair process and Fair Credit Reporting laws. (Linkonis, Sr., 2017)

\section{Financial Institution Credit Practices and Financial Consequences}

Credit scores are now a "near-universal financial passport" (Guzelian et al., 2015, p. 1809) for meeting even the most basic human needs for safety, such as shelter and security of employment,family, health, and property. Credit scores are key to making substantively different financial decisions, e.g., students' loans and employment, and represent "how good you are at spending with debt" (p. 1813). In fact, "a 'good' credit score bearer is also a frequent debtor" (p. 1814).

Poor credit scores are detrimental to vulnerable populations and further worsens socioeconomic disparities. Businesses use credit reports to increase loan interest rates, impact housing and employment decisions, and target predatory practices towards persons with mental health issues (p. 1808-1809). Every financial institution maintains its own scoring mechanisms, and the value of the customer is based on the institution's credit score. A lender's highest profitability is realized from the lower score demographicthe higher the interest rates, the higher the yield (Linkonis, 2017). Borrowers with poor creditworthiness were especially hard-hit by the COVID-19 pandemic. Horath, Kay, and Wix (2021) found interest rates increased for borrowers with less creditworthiness who received "newly issued credit cards" (p. 1). This additional increase in interest rates adds to spiraling economic burdens because of increasing indebtedness.

Poor creditworthiness can negatively affect access to basic human needs, including housing, transportation, employment, and food. Struggling to meet basic needs can contribute significantly to financial stress, depression, psychological distress, and diminished well-being (Marum, Clench-Aas, Nes \& Raanaas, 2014, p. 601). Stress is related to socioeconomic status and is an indicator of health and wellbeing (Pearlin, 2010, p. 208), and financial stress was found to be associated with depression and anxiety (Dijkstra-Kersten et al., 2015, p. 660), economic hardship, and coping strategies (Friedline, 2020, p. 2). Hopelessness is an element of depression, and negative expectations and cognition are a stronger indicator of suicidal intent than depression (Kocalevent et al., 2016, p. 1). Poor creditworthiness is an indicator of and contributes to psychosocial and socioeconomic stressors that impact the financial well-being, health, and overall well-being of individuals, their families, and communities.

\section{Credit Scores}

FICO, Vantage, and three credit bureaus generate credit scores that financial institutions and businesses use to assess lending risks. The scoring systems are proprietary, undisclosed, secret algorithms (Guzelian et al. p. 1811) used to allocate creditworthiness and credit unworthiness designations. While the numerical scoring systems differ, the credit scoring models are used for predictors of repayment (Linkonis, 2017) and "result in markedly different loan interest rates and contract terms than do wholesale denial of credit for lower scores" (Guzelian et al., p. 1813). Siddiqi (2017) lists strategies used to "maximize revenue and minimize bad debt...for high-risk applicants" (p. 13). The following strategies include:

- Declining credit/services if the risk level is too high; 
- Assigning a lower starting credit limit on a credit card or line of credit;

- Asking... applicant to provide a higher down payment or deposit for mortgages car loans;

- Charging a higher interest rate on a loan;

- Charging a higher premium on insurance policies;

- Adjusting payment terms for business customers;

- Asking....applicant to provide a deposit for...utility services;

- Denying international calling access from telecommunications companies;

- Selecting applicants for further scrutiny for potential fraudulent activity (p. 13).

Since the 2008 economic crisis, the relationship between borrowers and bankers declined, and objective criteria for lending money were required. "Loans are often packaged and sold to a third party, so objective data is critical" (Doroghazi, 2020, p. 157). Preferential consideration is given to high-scoring applicants, including "higher credit limits... upgrades to better...or additional products offered by the company.... Based on similar business considerations... (e.g., expected risk and profitability levels), different treatments can be tailored to existing accounts" (pp. 13-14). These treatments highlight the disparities that existamong customers as defined by credit scores. Siddiqi lists twelve examples, including:

- Increasing or decreasing credit limits on credit cards and lines of credit;

- Allowing some revolving credit customers to go beyond their credit limits for purchases;

- Allowing better customers to use credit cards even in delinquency while blocking the high-risk ones immediately (p. 14).

Scoring algorithms consist of weighted components making up the anatomy of the credit score. The anatomy is constant regardless of the scoring model. These include an individual's credit history (35\%), the age of payments on an account for the previous 24 months (15\%), the debt utilization ratio (30\%), the mix of loan and credit accounts (10\%) representing first and second mortgages, one installation loan, and two to five revolving credit card accounts, and the number of credit inquiries (10\%), scored between $0-5$ points, performed within a two year period (Linkonis, 2017). The debt-utilization ratio score is based on whether an account stays under $50 \%$ but ideally at $30 \%$ utilization. Utilizations over $50 \%$ of the credit limit negatively decrease the weighted debt-utilization ratio (2017).

The psychosocial and health impact of credit scoring practices is substantial. Guzelian et al. (2015) reference a report by researchers Christopher David and Janet Mantlers, stating their research "demonstrates the link between financial stress and declining health, marital breakups, parenteral neglect, and child abuse... and (sic) the effects of financial stress are largely indirect and attributable to depression" (p. 1823). Financial stress is the "non-ability to meet expenses ata certain point in time" (Brüggen et al., 2017, p. 3), whereas chronic financial stress is ongoing. Credit practices that target the most vulnerable contribute to chronic stress, for which there is no identifiable formula for relief or resolution.

The recent use of Machine Learning (ML) to guide decision-making processes and loan approvals introduces concerns about statistical fairness and the balance between lender profit and consumer fairness (Kozodoi, Jacob, and Lessmann, 2021). Machine Learning builds scoring models, risk scorecards that frame criteria for lending decisions. Several concerns regarding statistical fairness, fair credit scoring, civil rights, and "potential violation of anti-discrimination law" (pp.1-2) emphasize the need to establish fairness criteria in setting credit scoring data sets. Kozodoi et al. noted a 2018 report highlighting "the dangers of automated decision-making to the detriment of historically disadvantaged groups" (p. 1).

Machine Learning is also contributing to a new credit scoring system that incorporates the study of social media data. The advanced credit score calculation incorporates a legacy credit score, traditionally collected from financial institutions and other lenders, and a new emotional/social credit score (Kulkarni and Dhage, 2019). "The Advanced Credit Scoring model considers a person's cognitive ability along with the person's (sic) financial data" (p. 2379). To address low socioeconomic groups without credit, a project in Malaysia is underway to assess creditworthiness for individuals without a credit score and financial identity, using ML (Salem and Mahamad, 2020). Employing Android mobile devices and machine learning, 
credit scores are built for persons with an undocumented financial history, thus enhancing opportunities for improved socioeconomic status.

\section{RESEARCH STUDY}

\section{Methods}

A link to a sixteen-item online demographic survey was provided to participants before receiving the intervention. A link to an online survey was provided to participants that incorporated questions using four instruments related to the constructs being measured before receiving the intervention and after the initial phase of the intervention. Pretest posttest data was obtained from seventy-two participants and was used to test the research hypothesis and null hypotheses.

\section{Results}

The research hypothesis was supported. A quantitative analysis of the four hypotheses found there was a statistically significant relationship between participants' pretest and posttestresponses for the indicators of anxiety, depression, and hopelessness. The use of a shortened version of a financial well-being instrument and the lack of a longitudinal test in the pilot study was reflected in the data analysis, which did not reflect a statistically significant difference between the pretest and posttest scores.

\section{Methodology}

Examination of the research used a quasi-empirical research design, employing a pretest, posttest paired intervention, and a convenience sampling technique. The Wilcoxon signed-rank test was used to compare repeated measurements on a single sample between two paired groups. This non-parametric statistical test calculated the difference between the pretest and posttest scores of the sample population to analyze whether a statistically significant difference was found between the dependent samples.

\section{Findings}

There was a statistically significant difference in the indicators of anxiety, depression, and hopelessness for participants before receiving the intervention and in the indicators after participating in the initial phase of the intervention. The findings for each of the measures and relationship between the three measures were consistent with the research on the negative psychosocial construct of hopelessness, co-morbid conditions of hopelessness and depression, and the prevalence of anxiety and depression found in the general population and outpatient treatment. It was expected that the state of feeling worried and anxious for a sustained period of the past two weeks would demonstrate a statistically significant positive change between the pretest and posttest sample.

Responses suggested that the initial phase of the intervention conducted over the first 45-days of client services had the most significant effect on reducing worry among the respondents as measured by the GAD2 anxiety instrument. Respondent was asked how often he or she had been bothered by being anxious or being worried over the past two weeks. Figure 1 shows the positive changes by item. The combined total of worry, and both worry and anxiety represented $78 \%(\mathrm{n}=29)$ of the respondents were less bothered by worry during the past two weeks, including the day of the response.

The PHQ-4 depression instrument consisted of four questions, two of which included the GAD-2 anxiety items. The two additional items asked how often respondents had been bothered by feeling down, depressed, or hopeless and how often bothered by having little interest or pleasure in doing things over the past two weeks. Figure 2 shows the composite totals by item. Sixty percent $(n=43)$ of the total sample of 72 participants responded with a positive change on one or more of the items between the pretest and posttest. Of those that responded with a positive change to only one of the four questions, $55 \%(\mathrm{n}=22)$ of the respondents $(\mathrm{R}=40)$ responded with a positive change between the pretest and posttest survey. Figure 3 shows that of this group, positive changes across items were anxiety at $12.5 \%(n=5)$, worry at $32.5 \%(n=11)$, depression at 10\% $(n=4)$. Beck's Hopeless Scale Short (BHS-S) consisted of three statements. Respondents were asked to answer true or false based on whether the statement described his or her attitude for the past 
week, including today. Figure 4 shows positive changes by item. Figure 4 illustrates that the greatest percentage, $37 \%(n=22)$, was in response to the statement "things just won't work out the way I want them to."

\section{FIGURE 1 \\ ANXIETY: POSITIVE CHANGES BY ITEM}

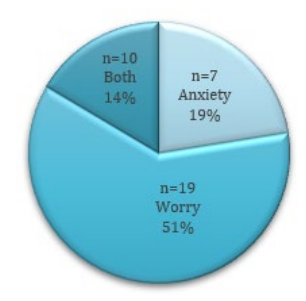

FIGURE 2

DEPRESSION COMPOSITE TOTALS: POSITIVE CHANGES BY ITEM

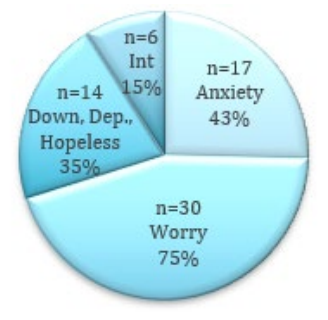

FIGURE 3

DEPRESSION: POSITIVE INDICATOR FOR SOLELY ONE ITEM

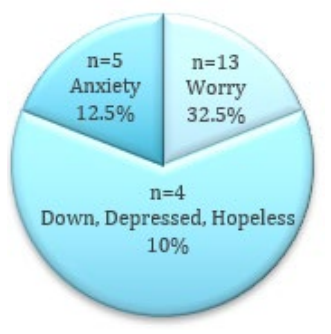

FIGURE 4

HOPELESSNESS: POSITIVE CHANGES BY ITEM

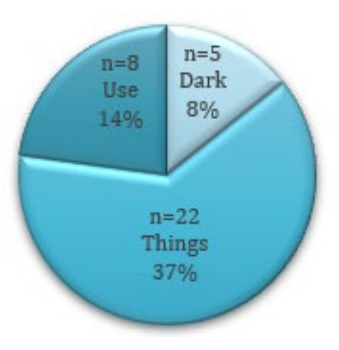




\section{CONCLUSION}

The focus of this research addressed a social concern related to whether creditworthinessas defined by credit score ratings affected financial well-being and contributed to an increase in biopsychosocial stressors with the potential to further impact increased indicators of anxiety, depression, and hopelessness. While this study collected demographic data for and indicators of suicidal behavior, the number of veterans and active military included in the pilot study was insufficient for analyzing this construct's statistical significance. The pilot study supported the findings that creditworthiness impacts aspects of an individual's well-being as framed by financial well-being and psychosocial indicators of the negative cognitions of anxiety, depression, and hopelessness.

During the initial period of the experiment, it was clear to the researcher there was a need to reframe the credit scoring anatomy and algorithms, which define creditworthiness, to empirically measure the success of the credit restoration intervention's effectiveness in future studies. The CFPB's Financial WellBeing Report (2015) cited many factors that influence individual financial well-being, including financial behaviors, financial knowledge, personal traits, social and economic environment, and life stages (pp. 2343). Several recent research studies also cite different, measurable indicators of wellbeing (e.g., Barrett et al., 2021; Cherney et al., 2020; Friedline et al., 2020; Iannello et al., 2021; Sorgente et al. 2019). Creditworthiness, as primarily defined by credit scores, needed further examination to understand the role of credit scores in addition to other wellbeing and financial wellbeing factors.

A Credit Restoration ScoreC (CRS) was designed and copyrighted by Robert Linkonis, Sr. and Cathie Hughes to further understand the impact of credit scores on well-being. Credit Restoration Associates tested the CRS instrument during and after the research pilot study. Case studies included five CRS audits conducted at different stages of the credit restoration process.

FIGURE 5

\section{CRS AUDIT LIFECYCLE}

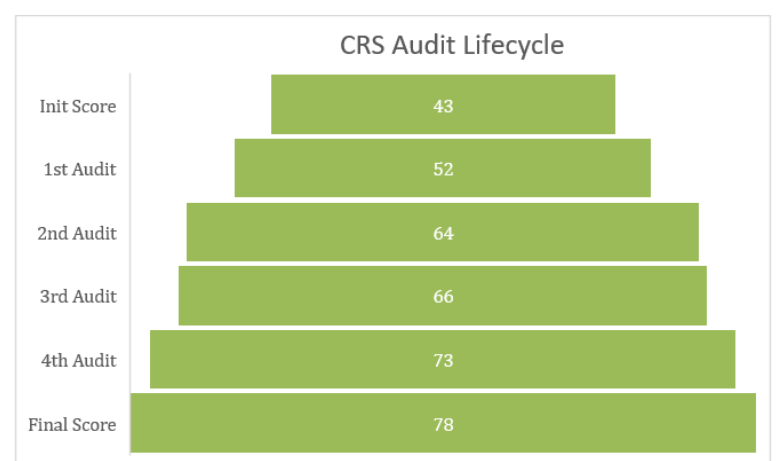

The CRS $\odot$ measures the progress of a client throughout the credit restoration process. A baseline is established at intake. Additional audits are performed at four points during the process that coincides with key timeframes related to the Fair Credit Reporting Act (FCRA) and the regulation of information in consumer credit reports. Figure 5 illustrates the scoring results for client number 1256 at each audit point. 


\section{FIGURE 6 \\ CRS CASE STUDY CREDITWORTHINESS RESULTS}

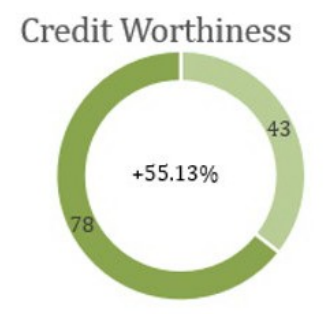

" CRS Initial Score " CRS Final Score

Figure 6 illustrates the initial CRS score of 43 points and the final score of 78 points, representing a $55.13 \%$ increase in creditworthiness indicators.

Credit restoration is part of an interdisciplinary, collaborative continuum of care that can positively contribute to reducing debt and the financial stress and psychological indicators associated with indebtedness. The CRS@ will be used in a more extensive longitudinal study to analyze creditworthiness as a measurable construct in addition to the psychosocial constructs for anxiety, depression, hopelessness, and suicidal behaviors. This researcher's study on creditworthiness addressed important and current societal issues facing millions of people in the United States. Two prominent issues included the national and veteran suicide rates and credit reporting reform legislation. Suicide rates are at an all-time high in the United States. According to recent CDC data (National Center for Health Statistics, 2018), the U.S. suicide rate is at its highest in fifty years and becoming widely accepted in America. Veteran suicide rates are 1.5 times that of non-veterans, with an average of twenty who die by suicide per day. In 2020, the spread of the COVID-19 virus touched every sector of society in the America. According to the John Hopkins Psychiatry Guide "certain groups may be more vulnerable to the effects of the pandemic and experience increased suicide rates" (Suicide risk in the COVID-19 pandemic, 2021). The second issue is an imminent need for credit reporting reform legislation. In October 2017, a Financial Services Committee held a hearing on credit reporting failures (U.S. House Committee on Financial Services, October 5, 2017). In February 2019, the Committee convened a hearing to address "repairing the nation's broken credit reporting system and holding the major consumer credit bureaus accountable" (U.S. House Committee on Financial Services, February 26, 2019).

A more extensive follow-up longitudinal study needs to be conducted to address these and other national concerns. A longitudinal study could benefit several issues within the umbrella areas of population health, well-being, and other social determinants of health. Further study is needed on the application of a credit restoration intervention, as defined in this study, for improving well-being, across interdisciplinary fields of study and having important implications for psychology, health, economics, public policy, and society.

\section{REFERENCES}

Adler, N.E., Cutler, D.M., Jonathan, J.E., Galea, S., Glymour, M., Koh, H.K., \& Satcher, D. (2016). Addressing social determinants of health and health disparities (p.16).

Aish, A.M., \& Wasserman, D. (2001). Does Beck's Hopelessness Scale really measure several components? Psychological Medicine, 31(2), 367-372. https://doi.org/10.1017/S0033291701003300

American Psychiatric Association. (2013). Diagnostic and statistical manual of mental disorders fifth edition (5th ed.). Washington, D.C: American Psychiatric Publishing.

Artiga, S. (2018, May 10). Beyond health care: The role of social determinants in promoting health and health equity. Retrieved from https://www.kff.org/ 
Barcellos, S.H., \& Jacobson, M. (2015). The effects of Medicare on medical expenditure risk and financial strain. American Economic Journal. Economic Policy, 7(4), 41-70.

https://doi.org/10.1257/pol.20140262

Barnard, A. (2016). Sense of coherence: A distinct perspective on financial well-being. South African Journal of Economic and Management Sciences, 19(4), 647-660. https://doi.org/10.17159file:///2222-3436/2016/v19n4a12

Barr, D.A. (2019). Health disparities in the United States: Social class, race, ethnicity, and the social determinants of health (third edition). Johns Hopkins University Press.

Barrett, A.M., Hogreve, J., \& Brüggen, E.C. (2021). Coping with governmental restrictions: The relationship between stay-at-home orders, resilience, and functional, social, mental, physical, and financial well-being. Frontiers in Psychology, 11, 3996.

https://doi.org/10.3389/fpsyg.2020.577972

Bell, M.M., Nelson, J.S., Spann, S.M., Molloy, C.J., Britt, S.L., \& Goff, B.N. (2014). The impact of financial resources on soldiers' well-being. Journal of Financial Counseling and Planning, 25(1), 41-52.

Berger, L.M., Collins, J.M., \& Cuesta, L. (2016). Household debt and adult depressive symptoms in the United States. Journal of Family and Economic Issues; New York, 37(1), $42-57$. http://dx.doi.org/10.1007/s10834-015-9443-6

bin Hassan, M.F., Hassan, N.M., Kassim, E.S., \& Said, Y.B.U. (2021). The relationship between financial wellbeing and mental health: A systematic literature reviews. Asia Proceedings of Social Sciences, 7(2), 92-95. https://doi.org/10.31580/apss.v7i2.1780

Bonomi, A.E., Trabert, B., Anderson, M.L., Kernic, M.A., \& Holt, V.L. (2014). Intimate partner violence and neighborhood income: A longitudinal analysis. Violence Against Women, 20(1), 42-58. https://doi.org/10.1177/1077801213520580

Bousfield, J., Phillips, W., D’Angelo, C., \& van Stolk, C. (2021). Workplace financial wellbeing interventions for young workers. Rand, 17. Retrieved from https://www.rand.org/pubs/ research_reports/RRA839-1.html

Britt, S.L., Canale, A., Fernatt, F., Stutz, K., \& Tibbetts, R. (2015). Financial stress and financial counseling: Helping college students. Journal of Financial Counseling and Planning, 26(2), 172186

Brown, S.M., Doom, J.R., Lechuga-Peña, S., Watamura, S.E., \& Koppels, T. (2020). Stress and parenting during the global COVID-19 pandemic. Child Abuse \& Neglect. https://doi.org/10.1016/j.chiabu.2020.104699

Brüggen, E.C., Hogreve, J., Holmlund, M., Kabadayi, S., \& Löfgren, M. (2017). Financial well-being: A conceptualization and research agenda. Journal of Business Research. https://doi.org/10.1016/j.jbusres.2017.03.013

Cherney, K., Rothwell, D., Serido, J., \& Shim, S. (2020). Subjective financial well-being during emerging adulthood: The role of student debt. Emerging Adulthood, 8(6), 485-495. https://doi.org/10.1177/2167696819879252

Comerton-Forde, C., de New, J., Salamanca, N., Ribar, D.C., Nicastro, A., \& Ross, J. (2020). Measuring financial wellbeing with self-reported and bank-record data (SSRN Scholarly Paper ID 3737273; p.86). Social Science Research Network. https://doi.org/10.2139/ssrn.3737273

Consumer Financial Protection Bureau. (2015). Financial well-being: The goal of financial education. [Government Agency]. Retrieved from https://www.consumerfinance.gov/

Danes, S.M., Garbow, J., \& Jokela, B.H. (2016). Financial management and culture: The American Indian case. Journal of Financial Counseling and Planning, 27(1), 61-79. https://doi.org/10.1891/1052-3073.27.1.61

Dijkstra-Kersten, S.M., Biesheuvel-Leliefeld, K.E., van der Wouden, J.C., Penninx, B.W., \& van Marwijk, H.W. (2015). Associations of financial strain and income with depressive and anxiety disorders. Journal of Epidemiology and Community Health, 69(7), 660-665. 
Doroghazi, R.M. (2020). Fico scores. The American Journal of Cardiology, 130, 157-158. http://dx.doi.org/10.1016/j.amjcard.2020.06.001

Dow, W.H., Godøy, A., Lowenstein, C.A., \& Reich, M. (2020). Can economic policies reduce deaths of despair? (Working Paper No. w25787). National Bureau of Economic Research. https://doi.org/10.3386/w25787

Elbogen, E.B., Johnson, C.S.C., Wagner, H.R., Newton, V.M., \& Beckham, J.C. (2012). Financial wellbeing and post-deployment adjustment among Iraq and Afghanistan war veterans. Military Medicine, 177(6), 669.

Frankham, C., Richardson, T., \& Maguire, N. (2020). Psychological factors associated with financial hardship and mental health: A systematic review. Clinical Psychology Review, 77, 101832. https://doi.org/10.1016/j.cpr.2020.10183

Fraser, L., Burnell, M., Salter, L.C., Fourkala, E-O., Kalsi, J., Ryan, A., ... Menon, U. (2014). Identifying hopelessness in population research: A validation study of two brief measures of hopelessness. BMJ Open, 4(5), e005093. https://doi.org/10.1136/bmjopen-2014-005093 subgroup

Frasquilho, D., Matos, M.G., Salonna, F., Guerreiro, D., Storti, C.C., Gaspar, T., \& Caldas-de-Almeida, J.M. (2016). Mental health outcomes in times of economic recession: A systematic literature review. BMC Public Health, 16(1), 115. https://doi.org/10.1186/s12889-016-2720-y

Friedline, T., Chen, Z., \& Morrow, S. (2020). Families' financial stress \& well-being: The importance of the economy and economic environments. Journal of Family and Economic Issues. https://doi.org/10.1007/s10834-020-09694-9

Gerrans, P., Speelman, C., \& Campitelli, G. (2014). The relationship between personal financial wellness and financial well-being: A structural equation modelling approach. Journal of Family and Economic Issues, 35(2), 145-160. https://doi.org/10.1007/s10834-013-9358-z

Ghina, A.A., \& Sukarno, S. (2021). Household finances and social comparison: Determinants of financial well-being in Indonesia. Journal of Socioeconomics and Development, 4(1), Article 1. https://doi.org/10.31328/jsed.v4i1.2223

Gray, D. (2013). Household finances, well-being and subjective financial situation: An empirical analysis of household survey data (Dissertation). University of Sheffield,England. Retrieved from http://etheses.whiterose.ac.uk/id/eprint/5142

Guzelian, C.P., Stein, M.A., \& Akiskal, H.S. (2015). Credit scores, lending, and psychosocial disability. Boston University Law Review, 95, 1807-1868. https://doi.org/10.1016/j.paid.2010.06.006

Hawton, K., i Comabella, C.C., Haw, C., \& Saunders, K. (2013). Risk factors for suicide in individuals with depression: A systematic review. Journal of Affective Disorders, 147(1), 17-28.

Hoge, G.L. (2014). Measuring financial strain in the lives of survivors of Intimate Partner Violence. In Society for Social Work and Research 18th Annual Conference: Research for Social Change: Addressing Local and Global Challenges. Retrieved from https://sswr.confex.com/sswr/2014/webprogram/Paper21332.html

Huen, J.M., Ip, B.Y., Ho, S.M., \& Yip, P.S. (2015). Hope and hopelessness: The role of hope in buffering the impact of hopelessness on suicidal ideation. PloS One, 10(6), e0130073. Retrieved from https://doi.org/10.1371/journal.pone.0130073

Iannello, P., Sorgente, A., Lanz, M., \& Antonietti, A. (2021). Financial well-being and its relationship with subjective and psychological well-being among emerging adults: Testing the moderating effect of individual differences. Journal of Happiness Studies, 22(3), 1385-1411. https://doi.org/10.1007/s10902-020-00277-x

Institute of Medicine. (2014). Capturing Social and Behavioral Domains and Measures in Electronic Health Records: Phase 2. Washington, D.C: The National Academies Press. Retrieved from https:/www.nap.edu/catalog/18951/capturing-social-and-behavioral- domains-and-measures-inelectronic-health-records

Involution Studios LLC. (2017). Determinants of health. Retrieved from http://www.goinvo.com/features Joo, S. (2008). Personal financial wellness. In J.J. Xiao (Ed.), Handbook of Consumer Finance Research (pp. 21-33). New York: Springer. https://doi.org/10.1007/978-0-387-75734-6_2 
Joo, S., \& Bagwell, D.C. (2003). Tools for the financial professional: Personal financial wellness. Journal of Personal Finance, 2(1), 39-53.

Kocalevent, R.-D., Finck, C., Pérez-Trujillo, M., Sautier, L., Zill, J., \& Hinz, A. (2016). Standardization of the Beck Hopelessness Scale in the general population. Journal of Mental Health, pp. 1-7. https://doi.org/10.1080/09638237.2016.1244717

Kozodoi, N., Jacob, J., \& Lessmann, S. (2021). Fairness in credit scoring: Assessment, implementation and profit implications. Retrieved from http://arxiv.org/abs/2103.01907

Kroenke, K., Spitzer, R.L., Williams, J.B.W., \& Löwe, B. (2009). An ultra-brief screening scale for anxiety and depression: The PHQ-4. Psychosomatics, 50(6), 613-621. https://doi.org/10.1016/S0033-3182(09)70864-3

Kulkarni, S.V., \& Dhage, S.N. (2019). Advanced credit score calculation using social media and machine learning. Journal of Intelligent \& Fuzzy Systems, 36(3), 2373-2380. https://doi.org/10.3233/JIFS169948

Kurowski, Ł. (2021). Household's over indebtedness during the Covid-19 crisis: The role of debt and financial literacy. Risks, 9(4), 62. https://doi.org/10.3390/ risks9040062

Lanz, M., Sorgente, A., \& Danes, S.M. (2020). Implicit family financial socialization and emerging adults' financial well-being: A multi-informant approach. Emerging Adulthood, 8(6), 443-452. https://doi.org/10.1177/2167696819876752

Liang, L., \& S., P.N. (M.D). (2021). Suicide risk in the COVID-19 pandemic. Johns Hopkins Psychiatry Guide. Retrieved April 10, 2021, from https://www.hopkinsguides.com/hopkins/view/Johns_Hopkins_Psychiatry_Guide/787393/ all/Suicide Risk in the COVID 19 Pandemic?refer=true

Linkonis, R.W., Sr. (2017, July 12). Credit repair, credit restoration, and the Fair Credit Reporting Act [Interview].

Linton, M-J., Dieppe, P., Medina-Lara, A., Watson, L., \& Crathorne, L. (2016). Review of 99 self-report measures for assessing well-being in adults: Exploring dimensions of well-being and developments over time. BMJ Open, 6(7), e010641. https://doi.org/10.1136/bmjopen-2015010641

Löwe, B., Wahl, I., Rose, M., Spitzer, C., Glaesmer, H., Wingenfeld, K., . . Brähler, E. (2010). A 4-item measure of depression and anxiety: Validation and standardization of the Patient Health Questionnaire-4 (PHQ-4) in the general population. Journal of Affective Disorders, 122(1), 86-95

Lundberg, O. (2020). Next steps in the development of the social determinants of health approach: The need for a new narrative. Scandinavian Journal of Public Health, 48(5), 473-479. https://doi.org/10.1177\%2F1403494819894789

Marum, G., Clench-Aas, J., Nes, R.B., \& Raanaas, R.K. (2014). The relationship between negative life events, psychological distress and life satisfaction: A population-based study. Quality of Life Research, 23(2), 601-611. https://doi.org/10.1007/s11136-013-0512-8

National Center for Health Statistics. (2019, February 14). Suicide mortality in the United States, 19992017. NCHS Data Brief. Retrieved November 30, 2018, from https://www.cdc.gov/nchs/products/ databriefs/db330.htm

Osborn, C.Y., Kripalani, S., Goggins, K.M., \& Wallston, K.A. (2017). Financial strain is associated with medication nonadherence and worse self-rated health among cardiovascular patients. Journal of Health Care for the Poor and Underserved, 28(1), 499-513. https://doi.org/10.1353/hpu.2017.0036

Overholser, J., \& Ridley, J.A. (2016). From sad to worse: Mood disorders and suicide risk. In Advancing the science of suicidal behavior: Understanding and intervention (pp. 373-390). New York: Nova Science Publishers.

Pearlin, L.I. (2010). The life course and the stress process: Some conceptual comparisons. The Journals of Gerontology Series B: Psychological Sciences and Social Sciences, 65(2), 207-215. https://doi.org/10.1093/geronb/gbp106 
Raab, P.A., Mackintosh, M-A., Gros, D.F., \& Morland, L.A. (2015). Impact of co-morbid depression on quality of life in male combat Veterans with post-traumatic stress disorder. Journal of Rehabilitation Research and Development, 52(5), 563-576. https://doi.org/10.1682/JRRD.2014.05.0130

Răileanu-Szeles, M. (2015). Explaining the dynamics and drivers of financial well-being in the European Union. Social Indicators Research, 120(3), 701-722. https://doi.org/10.1007s11205-014-0612-z

Roy-Byrne, P. (2015). Treatment-refractory anxiety; definition, risk factors, and treatment challenges. Dialogues in Clinical Neuroscience, 17(2), 191-206

Sabri, M.F., \& Zakaria, N.F. (2015). The influence of financial literacy, money attitude, financial strain and financial capability on young employees' financial well-being. Pertanika Journal of Social Sciences \& Humanities, 23(4), 827-848

Salem, A.S., \& Mahamad, S. (2020). Piteh: Providing financial identities to those without credit score. 2020 International Conference on Computational Intelligence (ICCI), pp. 159-162. https://doi.org/10.1109/ICCI51257.2020.9247779

Salignac, F., Hamilton, M., Noone, J., Marjolin, A., \& Muir, K. (2020). Conceptualizing financial wellbeing: An ecological life-course approach. Journal of Happiness Studies, 21(5), 1581-1602. https://doi.org/10.1007/s10902-019-00145-3

Schwab-Reese, L.M., Peek-Asa, C., \& Parker, E. (2016). Associations of financial stressors and physical intimate partner violence perpetration. Injury Epidemiology, 3(1), 6. https://doi.org/10.1186/s40621-016-0069-4

Serafini, G., Pompili, M., Innamorati, M., Dwivedi, Y., Shomron, N., \& Girardi, P. (2016). MicroRNAs, major affective disorders and suicidal behaviour. In MicroRNA and Non-Coding RNA: Technology, developments and applications (Vol. 1, pp. 121-146). NovaScience Publishers, Inc.

Siddiqi, N. (2017). Intelligent credit scoring: Building and implementing better credit risk scorecards (2nd ed.). Hoboken, New Jersey: John Wiley \& Sons.

Son, J., \& Wilson, J. (2015). The psychosocial processes linking income and volunteering: Chronic financial strain and well-being. In Sociological Forum (Vol. 30, pp. 1059-1081). Wiley Online Library. https://doi.org/10.1111/socf.12208

Sorgente, A., \& Lanz, M. (2019). The multidimensional subjective financial well-being scale for emerging adults: Development and validation studies. International Journal of Behavioral Development, 43(5), 466-478. https://doi.org/10.1177/0165025419851859

Sorgente, A., Totenhagen, C.J., \& Lanz, M. (2021). The use of the intensive longitudinal methods to study financial well-being: A scoping review and future research agenda. Journal of Happiness Studies. https://doi.org/10.1007/s10902-021-00381-6

Starkey, A.J., Keane, C.R., Terry, M.A., Marx, J.H., \& Ricci, E.M. (2013). Financial distress and depressive symptoms among African American women: Identifying financial priorities and needs and why it matters for mental health. Journal of Urban Health, 90(1), 83-100. https://doi.org/10.1007/s11524-012-9755-x

Sweet, E., Nandi, A., Adam, E.K., \& McDade, T.W. (2013). The high price of debt: Household financial debt and its impact on mental and physical health. Social Science \& Medicine, 91, 94-100. https://doi.org/10.1016/j.socscimed.2013.05.009

The Assessment and Management of Risk for Suicide Working Group. (2013). Assessment and Management of Patients at Risk for Suicide (2013) - VA/DoD Clinical Practice Guidelines (General Information). Washington, D.C: Department of Veteran Affairs and Department of Defense. Retrieved from https://www.healthquality.va.gov/ guidelines/MH/srb/

Thompson, S. (2015, July). Understanding the relationship between debt problems and psychological distress (Doctoral Dissertation). University of East London, England. Retrieved from http://ethos.bl.uk/OrderDetails.do?uin=uk.bl.ethos.667980

Tucker-Seeley, R.D., Mitchell, J.A., Shires, D.A., \& Modlin, C.S., Jr. (2015). Financial hardship, unmet medical need, and health self-efficacy among African American men. Health Education \& Behavior, 42(3), 285-292. https://doi.org/10.1177/ 1090198114557125 
Turunen, E., \& Hiilamo, H. (2014). Health effects of indebtedness: A systematic review. BMC Public Health, 14(1), 489.

U.S. House Committee on Financial Services. (2017, October 5). At Equifax hearing, financial services democrats secure second hearing on credit reporting failures. Retrieved from https://financial services.house.gov/

U.S. House Committee on Financial Services. (2019, February 26). Who's keeping score? Holding credit bureaus accountable and repairing a broken system. Retrieved from https://financial services.house.gov/

Valentino, S.W., Moore, J.E., Barcellos, S.H., \& Jacobson, M. (2015). The effects of Medicare on medical expenditure risk and financial strain. American Economic Journal. Economic Policy, 7(4), 41-70. https://doi.org/10.1257/pol.20140262

WHO | The determinants of health. (n.d.). [Government Agency]. Retrieved from http://www.who.int/ hia/evidence/doh/en/

Xiao, J.J. (2016). Consumer financial capability and well-being. In Handbook of Consumer Finance Research (pp. 3-17). Springer. Retrieved from http://link.springer.com/chapter/10.1007/978-3319-28887-1_1

Zhang, J., \& Li, Z. (2013). The association between depression and suicide when hopelessness is controlled for. Comprehensive Psychiatry, 54(7), 790-796.

https://doi.org/dx.doi.org/10.1016/j.comppsych.2013.03.004 